\title{
E havia uma ditadura cis-hétero-militar? ${ }^{1}$
}

(Is it true there was a cisgender-heterosexual-military dictatorship in Brazil?)

(¿Y había una dictadura cis-hetero-militar?)

ISSN: $2358-0844$

n. 16, v. 2

set.2021-dez.2021

p. $17-42$

Rick Afonso-Rocha ${ }^{2}$

RESUMO: Renan Quinalha foi o primeiro pesquisador a utilizar a expressão “ditadura hétero-militar” para se referir à heterogeneidade das políticas sexuais (e de gênero) adotadas, ou pelo menos intensificadas, durante o período da última ditadura brasileira. Desde que defendeu sua tese, em 2017, Quinalha parece ter se tornado referência nacional obrigatória nos estudos de confluência entre "homossexualidades” e ditadura. Disso decorreu a popularização, tanto no meio acadêmico quanto na militância política, do uso dessa noção. É sobre as (im)pertinências teóricoepistemológicas dessa formulação que me inclino a argumentar.

PALAVRAS-CHAVE: Ditadura cis-hétero-militar. LGBT+. Cis-heterodissidências e ditadura.

\begin{abstract}
Renan Quinalha was the first to use the expression "heterosexual-military dictatorship" to describe the heterogeneity of sexual (and gender) policies adopted, or at least intensified, during the Brazilian military dictatorship. Since defending his PhD dissertation in 2017, Quinalha became the main national reference in studies on "homosexualities" and dictatorship, resulting in the popularized use of the term, both in academia and political activism. In this study, I explore the theoretical-epistemological (im)pertinences of such concept.
\end{abstract}

Keywords: Cisgender-heterosexual-military dictatorship. LGBTQ+. Gender and sexual dissidences and dictatorship.

Resumen: Renan Quinalha fue el primero investigador a utilizar la expresión “dictadura hetero-militar” para referirse a la heterogeneidad de las políticas sexuales (y de género) adoptadas o, por lo menos, intensificadas durante el periodo de la dictadura brasileña. Desde que defendió su tesis, em 2017, Quinalha se tornó referencia nacional obligatoria en los estudios de confluencia entre "homosexualidades" y dictadura. Eso resultó en la popularización de su noción, tanto en el medio académico como en la militancia. Es sobre las (im)pertinencias teórico-epistemológicas de esa noción conceptual que quiero argumentar.

Palabras clave: Dictadura cis-hetero-militar. LGBT+. Cis-hetero-disidencias y dictadura.

1 Gostaria de agradecer a Sara Wagner York, pela leitura tão atenta e crítica deste trabalho, bem como a Iago Moura, pelas ricas considerações, e a Isaías Carvalho, pela revisão final.

2 BICHA. Doutoranda e mestra em Letras: Linguagens e Representações pela UESC. Bacharela em direito (UESC). Advogada OAB/BA. [rarocha@uesc.br] 


\section{Contextualização}

Morremos não, somos assassinados.

Seja pelo genocídio fardado, ou pelo estado suicidado que as nossas mentes deixam: infelizes fatos. Mas é claro! (“Estamos presentes!”, Luna Souto Ferreira)

Em 2017, durante a escrita do meu trabalho de conclusão de curso sobre a coluna literária do jornal Lampião da Esquina como exercício do contra-direito de resistência, escrevi um texto para apresentar num Congresso de Ciências Sociais e Educação. Nessa apresentação, utilizei a expressão de Quinalha (2018) - “ditadura hétero-militar” - duas ou três vezes. Quantidade suficiente para causar um grande mal-estar. O foco daquele trabalho não era a sugestão de Quinalha, tomava-o como ‘opção’ teórica. Os mediadores não viram assim. Para eles, era um absurdo o uso de uma noção restritiva como aquela para fazer menção à complexidade da ditadura. "Utilize ditadura militar ou civil-militar”, recomendaram. Tentei alegar, sem muito êxito, que não era a totalidade ou a complexidade da ditadura que estava sendo convocada. Pelo contrário, a expressão marcava uma das especificidades daquele período, naquilo que tinha de global e específico: a produção de uma normalidade (cis-)heterossexual, no gesto de leitura que eu estava a empreender.

Decidi, então, melhor me apropriar daquela expressão. Era preciso entender o funcionamento da proposta. Minha hipótese inicial era a de que a noção conceitual elaborada por Quinalha respondia à mesma lógica descritivo-analítica de outros operadores de leitura, como heteronormatividade, de Michael Warner (1991), heterossexualidade compulsória, de Adrienne Rich (2010), regime heterossexual, de Ochy Curiel (2013), bem como heterossexualidade como regime político, de Monique Wittig (1982).

No mesmo período, lia algumas matérias publicadas no Lampião da Esquina sobre transexistências, ou, no termo defendido pela pensadora Dodi Leal (2018), sobre as transvestigeneridades, assim como lia artigos a respeito das vivências de sujeitos não-cis durante a ditadura. Percurso que me auxiliou em questionar se não poderíamos falar numa dimensão cissexista ou cisgênera presente na ditadura. Fui aos textos de Aguinaldo Silva (2016), Benjamin Cowan (2015), Fábio Lopes (2016), Helena Vieira e Fraccarolli (2018), Herbert Daniel (1982), James Green (2000), João Silvério Trevisan (2018), Luiz Morando (2015), Rafael Ocanha (2014; 2015), Rita Colaço Rodrigues (2012; 2015); aos relatórios da Comissão Nacional da Verdade (2014), das Comissões Estaduais do Rio de Janeiro (2015) e São Paulo (2015). Retornei também à tese de Quinalha e seus demais textos a respeito da ditadura. Em minha compreensão, tais leituras apontavam para a afirmação de que houve, no Brasil, políticas oficiais de produção ${ }^{3}$ da sexualidade e do gênero a partir da normalidade heterossexual, mas também cisgênera. Inclusive, 
constatando que nada de novo havia nisso, afinal, expressamente, aqueles textos afirmavam que as políticas sexuais e de gênero, no regime autoritário, foram acentuadas quando se tratava de vidas não-cis, sobretudo quando se tratava de vidas travestis.

Dei-me conta de que minha inquietação era pela ausência dessa marcação no discurso de Quinalha. Por que não falar numa “ditadura cis-hétero-militar”? Após diversas buscas, não encontrei, nas plataformas on-line ${ }^{4}$, nenhuma proposta de reescritura daquela noção em "ditadura cis-hétero-militar”. Então fiz um pequeno paper, que apresentei num ciclo de debates históricos, em 2018, com o título: “O nosso prazer é melhor? A representação da ditadura cis-hétero-militar na edição experimental do Lampião da Esquina”. Embora apresentasse a reescritura como uma formulação mais plástica que a empregada por Quinalha, essa não funcionava, em meu entender, como conceito. Era mais a verbalização de uma inquietação: por que não falar cis-hétero-militar? Por que silenciar ou omitir tal dimensão, que salta aos nossos olhos nos trabalhos que empregavam "hétero-militar”?

Em seguida, ainda em 2018, apresentei outro trabalho. Agora, num evento das Ciências Sociais, com o título: "E havia uma ditadura cis-hétero-militar? A emergência de um silenciamento". Em 2019, publiquei o artigo “Bichas inauguram a utopia: resistência homoerótica na literatura lampiônica” (AFONSO-ROCHA; MITIDIERI, 2019), que foi o primeiro trabalho escrito no qual apareceu a expressão, além da minha monografia (AFONSOROCHA, 2018). Como o foco desses trabalhos não foi a reescritura, limitei-me a afirmar que os dispositivos de sujeição atuantes sobre os sujeitos cis-heterodissidentes, na ditadura, produziam e afirmavam positivamente não apenas um corpo heterossexual, mas também um corpo cis. Isso porque era notório o acirramento da repressão direcionada às vidas transexuais, travestis e transgêneras, bem como dos efeitos de uma pressurização cisnormativa que produzia o corpo cis como única identidade de gênero aceitável porque biologicamente 'natural' e moralmente ‘correta' - o que já era conhecido, friso, pelos estudiosos da temática. Também afirmei que, embora Quinalha tenha notado a acentuação repressiva às trans-existências, o conceito 'héteromilitar’ parecia omitir ou ocultar a dimensão cisnormativa da tradicionalmente denominada ditadura brasileira. Isso porque, conforme Quinalha (2018, p. 31, grifo meu): “[...] se pode falar em uma ditadura hétero-militar, em que houve uma política sexual oficializada $e$ institucionalizada para controlar manifestações tidas como ‘perversões’ ou ‘desvios'”.

Em 2019, já cursando o mestrado em Letras, tive contato mais profundo com pensadores e pensadoras trans e travestis, a exemplo de Alexandre Peixe (PEIXE; MORELLI, 2018), Amara Moira (2017), Beatriz Bagagli (2016), Helena Vieira (VIEIRA; FRACCAROLLI, 2018), 
Jaqueline Gomes de Jesus (2018), João W. Nery (2018), Letícia Lanz (2015), Sara Wagner York (2020) e Viviane Vergueiro Simakawa (2015). Com essas subjetividades, pude, enfim, construir uma proposta conceitual mais consistente, acredito eu. Permitam-me desenhar seu quadrante.

\section{A emergência sócio-histórica do conceito}

Recentemente $^{5}$, quando o questionei a respeito da utilização de minha formulação (ditadura cis-hétero-militar), Quinalha afirmou que, embora achasse pertinente, soava-lhe anacrônico, uma vez que o surgimento do termo 'cis' teria ocorrido apenas na década de 1990, portanto, depois dos documentos analisados por ele. Por isso, na época, teria considerado pertinente não incluir tal morfema (cis).

Ainda mencionou que esteve atento ao debate gerado por alguns intelectuais trans ${ }^{6}$, mas que optou por 'hétero-militar', visto que considerou impróprio aglutinar, em sua formulação, uma palavra que não existia na época àquela por ele descrita. Pergunto-me: que referente é esse diretamente apreensível? Acredito que seria oportuno nos perguntarmos que noção de história e de linguagem licenciam o que Quinalha reconhece como possível e impossível de se dizer deste lugar de enunciador pesquisador. Eu ainda me pergunto: acaso se situaria ele, ilusoriamente, 'fora da história' do tempo presente?

É por esse motivo, igualmente, que Quinalha optou pela não utilização da sigla LGBT+ e seus derivados para se referir aos sujeitos, objetos culturais e ao próprio movimento naquele período. Tal sigla também surge na década de 1990, sendo constantemente modificada ao longo dos anos 2000 (FACHINI, 2005). A ‘opção’ de Quinalha tem como justificativa mostrada o fato de que, durante as décadas de 1960 e 1980, era comum que as dissidências sexuais e de gênero fossem narradas, inclusive pelas próprias pessoas não-cis-heterossexuais, como manifestações ou expressões da 'homossexualidade'. Por isso, o emprego, naquele período, do termo no plural 'homossexualidades'. Em relação a essa última 'opção', reconheço que a afirmei por algum tempo. Contudo, atualmente, concordo com Jacqueline Cabral (2017) ${ }^{7}$ que, ao analisar os

5 Em live realizada pelo projeto História em Quarentena, em 14 de abril de 2020. Disponível em: https://bit.ly/3kqxvfD. Acesso em: 9 dez. 2020.

6 Penso que Quinalha fazia referência à postura defendida pela filósofa Helena Vieira, em artigo publicado em conjunto com Yuri Fraccaroli, no qual afirmaram: "nos parece ser necessário tentarmos nos aproximar às perspectivas e entendimentos dos sujeitos para além dos limites formulados pelos enunciados discursivos sobre a homossexualidade, produzidos majoritariamente pelos saberes psimédicos, sendo importante destacar a pluralidade de sentidos formulados às categorias identitárias” (VIEIRA; FRACCAROLI, 2018, p. 375). Os autores, então, chamam atenção para o regime sexo-gênero e para aquilo que denominaram como 'homossexualidade tática', estratégia assumida por muitas trans-existências como performatividade para além do imperativo sexo-gêneroprática-desejo, até pela ausência de "entendimento que diferenciasse gênero e orientação sexual".

7 Helena Vieira e Yuri Fraccaroli (2018), em sentido similar, defenderam o uso da sigla LGBTTT, por entenderem que, como os agenciamentos por uma memória política partem sempre do seu tempo presente, o purismo linguístico, tal como é justificado, se desvelaria pouco eficaz. 
documentos produzidos por diversos órgãos da ditadura que versam direta ou indiretamente sobre os sujeitos dissidentes da cis-heteronormatividade, concluiu:

[...] 'homossexualidades' não dá conta da identificação dos sujeitos assim denominados nos documentos consultados, já que ali aparecem representados como lésbicas, gays, bissexuais, transexuais e travestis, separadamente. Daí que, não desdobrar por extenso os substantivos da sigla LGBT+ ao longo do texto apenas poupa alguns caracteres e linhas, mas também significa evitar um termo ainda mais generalizante, normativo e engessado no masculino como homossexualidades (CABRAL, 2017, p. 107).

O historiador Paul Veyne (2011, p. 20), certa vez, ao comentar a importância do pensamento foucaultiano para a historiografia, afirmou: "narrar a história é conceitualizar”. Quando ilusoriamente “escolhemos” determinados significantes (e não outros) para nos referirmos aos ditos eventos ou acontecimentos históricos, estamos conceitualizando. Dizer 'golpe’, e não ‘revolução’, ou dizer ‘intentona', e não 'revolta comunista’ (como Quinalha fez recentemente no evento da Boitempo $^{8}$ ) é engajar-se, queira-se ou não, num processo de significação calcado numa luta de e por significações ${ }^{9}$.

Ou, como nos ensinou Judith Butler (2019, p. 35-36, grifo meu): “Na teoria dos atos de fala, a performatividade é a prática discursiva que realiza ou produz aquilo que nomeia. [...] Em uma reformulação crítica do performativo, Derrida esclarece que esse poder não é função de uma vontade originadora, mas é sempre derivativo”. Com isso, podemos dizer que, quando nomeamos ou designamos algo, de uma forma ou de outra, participamos da construção de um referente. O poder tem uma dimensão semântico-criativa. Ele nomeia para criar, mas também nomeia para silenciar. A nomeação é uma forma de definir a existência do que é nomeado, conforme Mariani (1996).

Não que antes inexistia, mas a nomeação constitui seu registo no regime de inteligibilidade das relações de poder. Se o poder é semântico, não podemos, portanto, desconsiderar a existência de uma luta de significações. Como disse Bakhtin/Volochínov (1981, p. 46): “em todo signo ideológico confrontam-se índices de valor contraditórios. O signo se torna

8 Gravação da mesa "O que resta da ditadura?”, do Seminário Internacional Democracia em colapso?, ocorrido em 2019. A mesa foi composta por Maria Rita Kehl, Renan Quinalha e Janaína Teles. Foi Janaína quem chamou atenção para a narrativa de Quinalha, que se desculpou e disse: "foi como aprendi na escola: intentona comunista". A fala ocorre no momento 1:35:10 do vídeo. Disponível em: https://bit.ly/3xMZVVd. Acesso em: 9 mar. 2020.

9 Como destacou Bethania Mariani (1996), a utilização do significante 'intentona' pode indiciar inscrição numa formação discursiva conservadora, visto que reativa a memória do dizer, pela qual rearticulam-se sentidos anticomunistas, ao passo que se silenciam e se impedem sentidos outros, aqueles próprios das formações discursivas comunista, de esquerda ou progressista. Diante disso, pouco importa a suposta intenção do sujeito: "Ao se dizer intentona comunista, está-se necessariamente nesse agrupamento de discursos: aventura, fracasso e projeto" (MARIANI, 1996, p. 2000). Ao designar aquele evento como intentona, produziu-se o fechamento de sentidos na memória do discurso, de modo a reforçar e rearticular, no imaginário social, os discursos sobre os comunistas; discursos esses, como já alertou a autora, necessários ao projeto de construção da identidade nacional e de legitimação do período ditatorial. 
a arena onde se desenvolve a luta de classes”. A luta entre as forças de poder e de resistência se dá no interior do signo (aqui, pode-se dizer, da palavra), pela significação.

Não podemos escapar da moldura discursiva do presente, tampouco das filiações de sentido que são a sua partilha; analisamos, com nossos discursos, práticas mediadas. Dizer os fatos é também os produzir. Não há de fato um 'passado' como real precedente ao dizer. Se, como afirmou Foucault (2017), o discurso é imanente ao dispositivo, de modo que não podemos contorná-lo, somos condenados a viver no nosso tempo. Claro que cada um irá se relacionar com esse tempo de maneira particular. Por mais que os discursos forneçam a matéria-prima para a significação, a textualização decorre do encontro singular com a historicidade do sujeito leitor (FIORIN, 1988). A leitura é um encontro dialógico e dialético que põe em jogo diversas posições de sujeito: leitor real, leitor virtual, autor, crítica, tradição (ORLANDI, 2006). E, por mais que queiramos, nada podemos fazer a respeito disso. Lembremos: os sentidos não são estáticos, eles se movimentam. Orlandi (2006) diz que podem sempre ser outros, mas não quaisquer uns. Há, de outra parte, o imaginário que nos obriga sempre à ilusão da literalidade.

A análise histórica se manifesta por atravessamentos de diversas naturezas, levando em consideração tanto o processo quanto o contexto. A utilização de determinado termo ou conceito para descrever ou qualificar dado evento histórico não resulta de uma arbitrariedade do historiador, mas de uma não neutralidade da historiografia, devendo, portanto, levar em conta a singularidade do acontecimento discursivo.

Podemos pensar, rapidamente, na inadequação do argumento de que a mera utilização de um conceito fora do seu tempo seria anacrônico. O termo 'genocídio' surge em 1944 com os estudos de Raphael Lemki (IRVIN-ERICKSON, 2013). Sua proposta era descrever as práticas politicamente orientadas para os extermínios de determinados grupos ou raças. Já o termo ‘feudalismo' surge entre os séculos XVIII e XIX para descrever uma experiência sociopolítica e econômica passada. Seria impróprio utilizarmos o termo já que no período do 'feudalismo' ele não existia enquanto fato linguístico? Não poderíamos falar que os sistemas de plantation, século $\mathrm{XV}$, foram 'genocidas'? Como destaquei, embora a nomeação/designação produza sentidos outros sobre aquilo que nomeia, não significa, necessariamente, que, antes dela, aquele funcionamento específico ou realidade inexistiam. Alguns conceitos servem à sintetização, pela descrição linguística e/ou política, de determinados funcionamentos. Nisso, não resultam em processo estritamente interpretativo, mas em procedimento descritivo-analítico ${ }^{10}$.

Há aí uma questão linguística. As palavras não estão grudadas nas coisas, nos eventos ou nos acontecimentos. Não há sentido em si preso numa palavra ou num conceito, de modo que só 
poderíamos utilizá-los numa perspectiva etimológica e genética, ilusão que parece atravessar Quinalha. Os sentidos derivam. Ou melhor, a imagem acústica deriva, no mais das vezes, do conceito. Deriva porque se cuida de uma relação arbitrária e não necessária, que diz do fato de que a linguagem não reflete ou refrata o mundo, mas permite significá-lo criativamente (mais como difração). A ideia de que podemos falar de forma clara, de que as palavras são objetivas, de que a linguagem é transparente, de que podemos escapar ao anacronismo ou de que podemos acessar os acontecimentos e eventos históricos tais quais ocorreram, a depender apenas de certo rigor metodológico - ainda hoje defendida por alguns historiadores que desprezam a materialidade da linguagem e o complexo campo dos estudos discursivos - não passa de um dos efeitos castradores dos processos de veridicção e do trabalhar dos dispositivos.

Parece-me que essa posição crítica rejeita um historicismo absoluto afeito às correntes historiográficas positivistas e marxista gramsciana, segundo as quais os conceitos e análises sócio-históricas estariam presas ao período na qual foram gestadas. Logo a história não comportaria formulações gerais e abstratas aplicáveis ao estudo de períodos históricos diferentes. Em resumo: longe do purismo linguístico, “a história pode sim ser analisada a partir de conceitos abstratos e muito gerais que transcendem diferentes e prolongados períodos históricos situados em áreas geográficas as mais variadas” (BOITO JÚNIOR, 2016, p. 155).

O signo é arbitrário, ou melhor, há língua ou, de modo mais amplo, há simbólico! Fato da castração simbólica frequentemente recalcado. Só isso bastaria para questionar o discurso duro do anacronismo. Fora isso: há história, não como cronologia, mas como lugar de inscrição da língua/simbólico para haver significação, isto é, história como interdiscurso (ORLANDI, 2006). Em outras palavras, devemos nos atentar ao dispositivo de legibilidade (AFONSO-ROCHA, 2021). Pensar em sentidos previamente dados e inalteráveis seria desconsiderar a opacidade da língua, do real e as condições sócio-históricas de produção dos sentidos, da própria leitura e, não nos esqueçamos, do sujeito.

A partir disso, entendo que Quinalha sucumbe ao efeito de real, por não o haver como tal, mas por buscar uma realidade imediatamente apreensível pelo testemunho fiel do arquivo empírico. Não há monumentalização, mas mergulho de cabeça na empiria do 'vivido', do ‘experienciado’.

O que está em jogo, entre a minha proposta e a de Quinalha, acredito, muito mais do que a simples adoção de uma partícula designativa (cis), são abordagens distintas. Enquanto, em minhas análises, trabalho o poder como produção, considerando a repressão como um dos seus 
efeitos produtivos e tomo o documento numa perspectiva serial, visando sua monumentalização ${ }^{11}$, Quinalha $(2017,2018)$, como leio, a partir de um tratamento estritamente empírico dos materiais, inscreve-se numa filiação que toma o poder como estritamente negativo, jurídico. Embora se aproxime da ideia de estado ampliado (hegemonia), quando, por exemplo, chega a considerar uma dimensão produtiva do poder, logo coloca essa a serviço da interdição (a produção como efeito da proibição), numa perspectiva que eu chamaria historicista empirista.

É preciso distinguir radicalmente essas abordagens. Em sua perspectiva, Quinalha implicita uma noção de documento como dado, uma concepção de série cronológica que se relaciona a uma noção de história teleológica própria ao historicismo, como também uma noção de linguagem como transparência e de língua como instrumento. Além disso, parece faltar a Quinalha uma teoria do sujeito como efeito, o que o leva a afirmar uma perspectiva historicista, continuísta, calcada na transparência, fincada na filosofia da experiência e tendo como base a empiria do documento. Embora em alguns momentos pontuais cite Foucault, aproximando-se de uma perspectiva historiográfica pós-estruturalistas ou descontinuísta, parece-me que não dá consequência a esses aportes epistemológicos. De tal forma que se filia mais consistentemente a uma perspectiva epistemológica que idealiza as ditas fontes e se convola a afirmar o império do documento, em sua suposta condição de testemunha dos fatos tais quais teriam ocorrido.

Com Foucault, relaciono-me de outra maneira com a história, pela via da descontinuidade, construindo as séries que compreendo como possíveis de ler a partir do jogo dinâmico entre o regime de enunciabilidade e o campo de visibilidade, ao passo que tomo a linguagem como opacidade, ao trazer as mediações do simbólico e do imaginário. Disso resulta a afirmação de uma teoria do sujeito como efeito dos processos de sujeição e subjetivação, uma teoria da história como não cronológica, assim como uma teoria do discurso em sua relação com o não-discursivo, o que põe em jogo as opacidades que investem o sujeito enquanto efeito das relações de poder.

Falar que a ditadura foi heteronormativa é, a meu ver, demarcar tão somente que houve produção ${ }^{12}$ de uma 'normalidade' heterocentrada (orientação sexual). Consequentemente, dá-se primazia a um dizer sobre os acontecimentos em relação aos sujeitos não-heterossexuais, sejam eles cis ou trans, equacionando experiências muito diversas. Como se as condições reais das trans-existências não fossem, naquele período, vistas como problemáticas, desviantes, anormais

11 Com isso, significa que já não basta tentar exaurir as verdades dos documentos, muito menos assinalar seu valor expressivo, mas tensioná-los em seu interior: estabelecer séries, repartir em níveis, descrever relações, montar o arquivo audiovisual, conforme ensinou-nos Foucault (2008a) em sua arqueologia.

12 Contudo, é pertinente destacar que Quinalha não dá consequência à dimensão produtiva do poder. Sua analítica se dá pela repressão. Ele diz produção de outra maneira. Quando ele diz produção, em verdade, faz ver apenas a repressão. 
e não apresentassem singularidades distintas daqueles vivenciadas pelos desviantes sexuais. Tal equacionamento acaba por silenciar e omitir o acirramento das políticas de gênero de cisnormação e cisnormalização da vida (identidade de gênero, expressão de gênero e performance de gênero).

Nesse sentido, já tinha notado Amara Moira (2017, p. 365-366) que

[...] numa sociedade profundamente cissexista, numa sociedade tão cissexista que sequer conseguisse enxergar o próprio cissexismo (de tão naturalizada que estava essa lei, de tão apagada que estava a sua origem, a sua razão), não haveria a menor possibilidade de pensarmos a existência material, concreta de pessoas trans.

A adoção do termo técnico 'cis’ no conceito 'hétero-militar' demarca exatamente isto: a cegueira provocada pelo cissexismo que, de tão naturalizado, impossibilita a reflexão a respeito de fenômenos específicos relacionados à existência material e concreta de trans-existências. Nas palavras das pensadoras Neon Cunha e Sara Wagner York (2020, grifo meu):

\begin{abstract}
'Cissexismo’ é o neologismo usado para condensar duas ideias colonizadoras, em que uma opera enquanto norma governamental (cisgeneridade) e a segunda atua enquanto caráter de dominação, hierarquização e inclusão de diferença (sexismo). Estes dois conceitos vão agir sobre processos de exclusão sobre o corpo que escapa da crença de que o gênero de pessoas cisgêneras é, de alguma forma, mais legítimo que aquele de pessoas transgêneras; aliado à misoginia, são marcadores importantes no apagamento do engajamento da população trans nas conquistas por direitos LGBTQI+.
\end{abstract}

De modo tal que reduzir as políticas de gênero às sexuais pode endossar a redução das identidades de gênero à orientação sexual, num dos efeitos daquilo que Dodi Leal (2018), em mais uma de suas corrupções de linguagem ${ }^{13}$, denominou academiCISmo.

Ainda que tomemos a indistinção real entre sexo e gênero proposta por Butler (2019) ${ }^{14}$, por que dar primazia ao sexo e falar em ditadura hétero-militar apenas? Poderíamos, com Butler, enfatizar a categoria de gênero, sempre como efeito de sentidos produzidos pelos dispositivos de veridicção de um sistema sexo-gênero. Dessa forma, poderíamos falar em uma ditadura cisgênero-militar ou cis-militar, algo parecido com que fez Viviane Vergueiro Simakawa (2015, p. 15, grifo meu) ao propor o conceito de cis-tema (CIStema ou cistema), sem precisar designar o heterossexismo latente numa expressão como “cistema heterossexista”, já que fincada em tal indistinção ${ }^{15}$ :

13 "Produzir corrupções de linguagem desnudando a cisnormatividade e abrir novas possibilidades aos existires de gênero são atividades que poderiam nos sugerir a sua aproximação com o sofismo” (LEAL, 2018, p. 124).

14 Filiação que, portanto, não subscreve a oposição imaginária entre sexo e gênero, enquanto oposição entre natureza e cultura, respectivamente, e permite tratar do sexo como um construto discursivo.

15 Inclusive, embora parta da indistinção entre sexo e gênero e 'eleja' o gênero como categoria analítica, Butler utiliza enfaticamente o conceito de imperativo ou matriz heterossexual, não dando consequência direta a sua própria 'escolha'. Por isso, algumas trans feministas 'optam' pela reescritura como imperativo cisgênero e heterossexual ou ainda imperativo cis-heterossexual. Sobre isso, ver a análise de Beatriz Bagagli (2014). Paul B. Preciado (2020), de forma mais coerente, acredito, utiliza a expressão ‘sistema sexo-gênero' ou regime de diferença sexual e de gênero. 
'Cistema-mundo’, uso-a enquanto referência a Grosfoguel (2012, 339), que caracteriza um '[c]istema-mundo ocidentalizado/cristianocêntrico moderno/colonial capitalista/patriarcal' que produz 'hierarquias epistêmicas' em que [...] perspectivas não cisgêneras são excluídas, minimizadas, ou silenciadas. A corruptela 'cistema', entre outras corruptelas do tipo, têm o objetivo de enfatizar o caráter estrutural e institucional - 'cistêmico' - de perspectivas cis+sexistas, para além do paradigma individualizante do conceito de 'transfobia'.

Friso: dizer que houve uma dimensão 'hétero-militar' faz passar a falsa percepção que uma pessoa trans heterossexual era, naquela época, perfeitamente reconhecida, ou seja, lida na transparência do 'natural'. O aparato repressivo apontaria apenas para práticas não heteronormadas, enquanto o aparato produtivo intensificaria a normalidade das práticas heterossexuais somente. Ainda que não seja isso que Quinalha aponte expressamente, visto que em sua argumentação mostrou como travestis, transexuais e demais pessoas não-cis tiveram suas vidas desmanteladas pelo regime autoritário, é um dos sentidos possíveis de serem lidos em sua formulação, de modo a desprezar as políticas de gênero intensificadas pela ditadura brasileira pela matriz cisgênera ${ }^{16}$ :

Mesmo que o entendimento identitário hegemônico da época não fizesse distinção entre homossexuais e travestis, compreendendo-os basicamente como graus distintos de um mesmo desvio, é possível percebermos que ser um homem gay era uma experiência diferente de ser travesti ou homossexual e assumir uma performatividade permanentemente feminina (VIEIRA; FRACCAROLI, 2018, p. 375).

Destacando a particularidades das trans-existências sob os anos de chumbo, Vieira e Fraccaroli (2018, p. 363) afirmaram que foram elas, juntamente as bichas efeminadas

[...] que se torna[ra]m os principais alvos de controle por parte das forças de controle e repressão, conformando uma política contra essa ameaça patológica (social e corporal) à segurança nacional, perigoso fator de vulnerabilidade política, baseada em ideais que remetem às próprias bases do sentimento anticomunista no país.

Desse modo, como destacou Sara Wagner York (2017, p. 89), é preciso: "repensar tais aspectos vivenciados com reflexões contínuas de abuso e estratégias de poder do Estado, por onde padrões cisgêneros binários [...] mantêm e sustentam práticas abusivas sobre pessoas excluídas e que seguem alheias nos conhecimentos de si mesmas”.

Esse funcionamento cisnormativo compareceu em diversos momentos na ditadura cishétero-militar brasileira. Vejamos alguns exemplos. Em abril de 1975, a letra da canção “Travesti Transexual da Transilvânia”, de Richard O’Brien, foi censurada pela “intenção clara

16 Sobre a dimensão cisnormativa da ditadura brasileira, ver os trabalhos de Luiz Morando (2015), Helena Vieira e Yuri Fraccaroli (2018), bem como o de Fábio Lopes (2016). Tais autores abordam as especificidades das transexistências nesse contexto, não as reduzindo às políticas sexuais como faz Quinalha (2015, 2017, 2018). Cabe frisar que reconheço a importância fundamental da obra de Quinalha, pois foi a partir dela e de sua atuação política que, desde 2015, houve interesse crescente pela temática. 
do autor em fazer a música uma apologia do homossexualismo”. No reexame, em maio do mesmo ano, realizado por outro censor, consta que "o conteúdo da música exalta o homossexualismo”, devendo, portanto, ser interditada (BRASIL, 1975a, 1975b). A canção integrava a versão brasileira do musical The Rocky Horror Show ${ }^{17}$.

Noutro episódio, também envolvendo trans-existências, em documento sobre “propaganda adversa, literatura no período de jan. a abr. de 1985”, vemos o livro de João Nery ser classificado, pelo Serviço Nacional de Informações (SNI), como literatura pornográfica, contrária aos ideais da 'revolução’: “'ERRO DE PESSOA - JOANA OU JOÃO’, de JOÃO W. NERY (sem registro), pseudônimo do autor, que conta sua vida de transexual, submetido a cirurgias ilegais para mudar de sexo, assumindo nova identidade e, atualmente, casado com uma mulher, desempenhando o papel de homem” (BRASIL, 1985, p. 5). Embora tente descaracterizar sua identidade de gênero (“cirurgia ilegal para mudar de sexo”), relacionando-a à pornografia e à ameaça subversiva, o documento acaba por reconhecer, paradoxalmente, essa mesma identidade: “pseudônimo do autor” (e não da autora), ao passo que indicia para a afirmação da performatividade do gênero: “assumindo nova identidade” "papel de homem”.

Entre as violências direcionadas às trans-existências estavam: extorsões por policiais, proibição de espetáculos públicos, censura, proibição de desfilarem no carnaval, fechamento de estabelecimentos nos quais se apresentavam, violência física em abordagens policiais, demissões, humilhações públicas, prisões arbitrárias, banimento de programas de televisão (pelo ‘mal exemplo’ à juventude), proibição de auto-organização política, cancelamento dos desfiles e eventos culturais (por ordem das Secretarias de Segurança Pública estaduais como em Minas Gerais e São Paulo), censura, incitação ao assassinato, espancamentos, tortura, desaparecimentos como relatado por Mônica, travesti entrevistada por Antonio Chrysóstomo no Lampião da Esquina (1978, p. 10) ${ }^{18}$ :

Tem um comissário, chamam de Black, que é o terror da Praça Tiradentes. Prende bicha, toma dinheiro, bate e manda embora. Se reclamar, somem com o viado. Tem uma, a Carminha, um[a] travesti lind[a], moren[a], precisava de ver, que arranjou encrenca e sumiram com ela. Acho que sequestraram, levaram pra São Paulo. Coitada da Carminha. Nunca mais ninguém ouviu falar nela.

17 Quinalha (2017, p. 87) faz uma interessante análise sobre o parecer de liberação do texto desse musical pela censura que considerou: "a androgenia (da peça) não quer dizer 'homossexualidade', agregando a informação de que 'FRANK FURST o vampiro bissexual não é um terráqueo travesti e sim um símbolo de uma entidade mítica (cosmogênica) que fugindo ao ritual do simbolismo usou fisicamente seus poderes (proibidos) e por isto foi condenado à morte, como as crianças gregas da antiguidade que possuíam tal sinal físico (hermafroditismo) próprio e inerente aos deuses'”.

18 Para uma abordagem mais específica dessas violências, ver Luiz Morando (2015) e Rita Colaço Rodrigues (2015). 
Num desses episódios, Luiz Morando (2015) descreveu que, em 1965, o diretor da Divisão de Divertimentos Públicos de São Paulo proibiu, por portaria, espetáculos de travestis e transexuais em boates, cabarés e estabelecimentos congêneres. Também em 1965, em Belo Horizonte, segundo Morando (2015. p. 55), a Polícia Civil fez circular, na imprensa local, ameaça de prisão aos “Os invertidos que saírem à rua usando batom, roupas justas e derem escândalos”. Em 1968, após divulgação, nos jornais belo-horizontinos, de que travestis estavam organizando uma passeata contra a brutalidade da polícia e contra o cancelamento do concurso Glamour Girl, o Secretário de Segurança Pública de Minas Gerais reagiu imediatamente e, em entrevista à imprensa, alertara: “se boneca fizer passeata, apanha” (p. 77). Consonante Morando (2015), o Secretário, quando perguntado o que as autoridades fariam, caso as travestis insistissem com a passeata, afirmou: “pau neles”.

Outra evidência desse cissexismo pode ser obtida no texto publicado no Lampião da Esquina sobre a travesti Verushka, na edição 10 de 1979. A matéria intitulada "Síndico quer Verushka usando gravata e paletó”, de Aguinaldo Silva, narra a perseguição pela qual Verushka estava passando em seu prédio, sendo inclusive proibida de usar o elevador social por suposta falta de decoro e desrespeito à “moral e aos bons costumes”. O síndico, Gérson Correria, sargento da marinha, de imediato, “a partir de sua posse [intimou Verushka:] el[a] só poderia continuar usando o elevador social do prédio se trocasse suas vestimentas por roupas ‘estritamente' masculinas” (SILVA, 1979, p. 3).

Em debate entre um dos editores do Lampião, Adão Acosta e Bamby Azevedo, leitora do jornal que se identificou como travesti, é possível visualizar o dissenso entre a defesa da homogeneidade em torno do significante homossexual, posição de Adão, e a defesa da diferenciação da identidade de gênero como marcador social de singularidade das vidas travestis, postura defendida por Bamby. Após um texto assinado por Acosta intitulado "Bom mesmo é carne de homem”, na coluna Bixórdia, na edição n 17 em outubro de 1979, no qual criticava as travestis, naquilo que identificava como uma prática de “querer ser mulher”, ao passo que tentava realocá-la como uma prática de "fazer a travesti”, sem a necessidade de sonhar em se transformar em mulher e usar silicone. Em seu relato, elogiava um concurso em que participou: “o interessante desta festa é que os rapazes estavam numa boa, não usavam silicone e pelo que parece não sonham em virar mulher” (ACOSTA, 1979, p. 16).

Bamby de Azevedo encaminhara resposta para ser publicada na coluna Cartas na mesa, na edição no 18 de novembro de 1979, intitulada “Travesti protesta”, reclamando, então, sua 
identidade de gênero como travesti devido às tecnologias corporais de prótese ${ }^{19}$ : "Eu sou travesti apenas porque tenho um pouco de busto à custa de hormônios, tenho o rosto bem feminino e cabelos compridos” (AZEVEDO, 1979, p. 19).

Em tréplica, como suplemento ao texto de Bamby de Azevedo, Adão Acosta respondeu que não era “contra os travestis ou qualquer minoria”, como também, numa estratégia persuasiva, de inclinação pedagógica, argumentou:

Um detalhe de sua cartinha: você diz que é travesti porque usou hormônio, tem rosto feminino e cabelo comprido? Conheço muitos rapazes que tem rosto feminino e cabelos compridos e são machões. Não seria o processo homossexual independente da aparência externa? Pense bem! (ACOSTA, 1979, p. 19, grifo meu).

Tal arremate ("pense bem”) pode denunciar uma atitude de superioridade, como se a reflexão dele (por ser homem, com nível superior) fosse mais densa, complexa e, portanto, mais verdadeira do que a de Bamby, travesti. É como se ele estivesse numa posição de ensinar a maneira correta de se perceber como dissidência sexual (apenas). Aí, há um efeito da matriz cisgênera. Esse diálogo pode ensejar questionamentos sobre a disputa de sentidos em torno das políticas identitárias, indiciando que, diferente do querem fazer ver alguns, a percepção das trans-existências como dimensões ou manifestações distintas de um mesmo ‘desvio’ não era harmonicamente aceita. Os indícios apontam para cisões de sentidos, para disputa de identidades, bem como contra a reafirmação imaginária de uma homogeneidade que há muito tenta se fazer real: a homossexualidade naturalizada e normalizadas.

Assim, se há indícios sobre a existência, no período, do questionamento sobre a homogeneização identitária como efeito da subsunção do sexo e do gênero à homossexualidade, não temos porque sustentar qualquer purismo linguístico. Purismo esse que, embora se justifique no intento de 'respeitar' a forma como aquelas existências supostamente se narravam e se entendiam, acaba por apagar singularidades discursivas (e não discursivas) que escapavam àquele funcionamento sociopolítico dominante. Como também tem como efeito re-idealizar uma homogeneidade imaginária cujo funcionamento biopolítico, como sabemos, está a serviço do sistema sexo-gênero, de modo a reduzir as identidades de gênero à orientação sexual, higienizando a 'homossexualidade'.

Afinal, se as trans-existências, bem como as bichas efeminadas e as sapatas masculinizadas ‘foram’ manifestações ou graus distintos de um mesmo ‘desvio’, é mais fácil

19 Ou: “Ao afirmar que é travesti por conta de seus atributos físicos, a leitora sugere que o 'ser' travesti estaria mais ligado ao uso de aparatos tecnológicos para alterar o corpo, de maneira 'definitiva', diferente de montar-se para um show e 'fazer' travesti” (CANABARRO; MEYRER, 2020, p. 20). 
fazer ver que essas expressões seriam, em verdade, apenas atitudes escandalosas ${ }^{20}$ reativas ao preconceito social, atitudes mais radicais e, por isso mesmo, não hegemônicas. Com isso, sustenta-se que tais 'expressões' seriam, em si, uma forma de chamar atenção, e não constituiriam existências singulares. Nega-se-lhes qualquer estatuto político-ontológico ou mesmo identitário. Esse raciocínio é usado para justificar a higienização da 'homossexualidade'21. O que se traduziria na possibilidade de limpar a homossexualidade a partir da 'aceitação'. No fundo, retirando essas ameaças, a sociedade perceberia que 'somos normais'. 'Somos' que se desvela como colonização das diferenças pela produção imaginária da homogeneidade identitária. Nessa lógica perversa, se os homossexuais fossem integrados, nada justificaria atitudes escandalosas (frise-se: minoritárias), ou pior: para serem integrados, precisariam eliminar essas ameaças sociais, mostrando a sociedade que ‘são bons sujeitos’.

É nesse sentido que recuso o termo 'homossexualidades' para me referir às dissidências sexuais e de gênero, uma vez que a imaginária 'identidade homossexual' repousa sobre a rejeição de outras possibilidades de existências dissidentes, assim como põe em jogo o sonho da integração gay pela higienização nos moldes cis-heteronormativos, naquilo que se traduz em mais violências contra existências que rejeitam tal subsunção normativa. Defendo que não marcar o funcionamento sociopolítico da matriz cisgênera, na chamada ditadura militar brasileira, seja, em alguma medida, silenciar essas violências.

Naquela perspectiva higienista: “a bicha pintosa é agressiva, agressividade que - diga-se de passagem - se compreende, pelas pressões que ela sofre, mas que não se justifica, em meu ponto de vista. Afinal, a velha história; dois erros não fazem um acerto” (MASCARENHAS, 1978, p. 9). Por isso, "as figuras da travesti, da bicha pintosa, da boneca e da bicha louca, aparecem muitas vezes como desestabilizadoras de uma construção de identidade homossexual masculina 'limpa', sem os ‘trejeitos' que os retirariam da normalidade” (CANABARRO; MEYRER, 2020, p. 19). Disso resulta que as tentativas de diferenciar o homossexual respeitável - aquele representante fiel da homossexualidade, que frente ao preconceito não toma o escândalo

20 O escândalo se desvela como forma-de-vida, que se assume ameaçadora e se explora como periculosidade bichasapatrans - na terminologia de Paco Vidarte (2019) - ao cis-tema. É a vida como escândalo, performada pelos filósofos cínicos, agora reclamada como corrupção política pelas vidas escandalosas, com a valorização das corporeidades, do desapego, do deboche e do escracho aos padrões cis-heteronormativos. É a coragem bichasapatrans que não aceita se normalizar e nem busca ser integrada. Tal qual como Diógenes de Sinope, em seu barril nu, diante do poder, afirmamos: “saia da frente do meu sol”. Ou, no poema de Susy Shock (2011), monstro mío: "Reinvindico: mi derecho a ser un monstruo que otros sean lo Normal”.

21 Segundo Néstor Perlongher (1993), a higienização da 'homossexualidade’ é marcada pelo desaparecimento da bicha (das dissidências sexuais e de gênero), da analidade, da passividade e da efeminação, bem como pela construção do corpo saudável e medicalizado, sendo o oposto do corpo debilitado pela aids ou do corpo afetado pela bichice. 
e a agressividade como ferramentas de luta - das bichas, das travas, das sapatonas, aqueles 'maus representantes da homossexualidade':

Assim, para Mascarenhas, 'há o homossexual comum e há o travesti, que em muitos casos são prostitutos e acabam se envolvendo com pequenos furtos ou drogas’, de forma que a 'imagem predominantemente atribuída ao homossexual na verdade corresponderia ao travesti e esta aproximação atrapalharia o movimento organizado, ${ }^{22}$ (CANABARRO; MEYRER, 2020, p. 23).

Diante da postura higienista de João Antônio Mascarenhas, fundador do Lampião da Esquina, cabe destacar que, embora o jornal tenha importante papel na luta LGBT+ e na construção da nossa memória política, por traduzir mediações do simbólico e do imaginário, constituindo-se num campo em disputa (polivalência discursiva) em diversos momentos; o periódico reproduz estereótipos e preconceitos em relação às trans-existências, em específico às travestis.

Sobre como o Lampião narrou tais existências, vale conferir o excelente e exaustivo trabalho de Ronaldo Canabarro e Marlise Regina Meyrer (2020) ${ }^{23}$. Os autores citam como exemplo o texto assinado por Mascarenhas, em resposta à crítica feita por um leitor, segundo o qual Mascarenhas desprezava as travestis e as bichas mais efeminadas. Em sua resposta, conforme Canabarro e Meyrer (2020), o lampiônico expôs que via a efeminação como efeito do machismo e, por isso, como uma estereotipação do 'homossexual'. Mascarenhas, então, sustentava que as “'bichas afetadas e os travestis’ introjetaram essa máxima machista e a reproduziam de forma inconsciente” (CANABARRO; MEYRER, 2020, p. 13).

Já em outro momento, o jornal publicou uma entrevista com Guy Hocquenghem, na edição 37, de julho de 1980, na qual o autor apontara que visualizava a prática das travestis brasileiras como revolucionária ${ }^{24}$ :

O impacto social, se você quiser, do movimento gay brasileiro, é nulo comparado não importa com qual travesti. O que chamo de Impacto social, para ser sociológico, é a importância da mensagem dada, seja pelo impacto, seja pelo humor, quando se passar um tipo. É evidente que [a] travesti é uma instituição brasileira, uma instituição desprezada, oprimida, mas urna instituição. O movimento gay é uma enorme brincadeira de alguns burgueses brancos, que querem fazes discursos, que não podem ir à boate se a boate é ou já foi dominada por travestis. Penso que a bicha brasileira nunca faria travesti, acho que isso seria impossível (HOCQUENGHEM, 1980, p. 6).

22 Os autores citam: a obra de Cristina Câmara, Cidadania e orientação sexual: a trajetória do grupo Triângulo Rosa, publicada pela Academia Avançada em 2002. Obra não consultada nesta pesquisa.

23 Também ver Edlene Silva e Alexandre Brito (2017).

24 A partir de 1980, vemos com mais força no jornal a presença de matérias sobre travestis, inclusive algumas capas. Será que por isso alguns afirmaram que o Lampião "começou elegante e terminou pornográfico" (KUCINSKI, 1991, p. 84)? É dessa época a edição do Lampião mais significativa sobre a temática travesti, conforme Canabarro e Meyrer (2020): o número 32, de 1981, que estampava: "Brasil: campeão mundial de travestis". 
A partir dos exemplos analisados, podemos dizer que as trans-existências foram produzidas como ameaças sociais, de modo a ocuparem o significante 'inimigo', dentro dos limites traçados pela Doutrina de Segurança Nacional: “os ideólogos [da ditadura] ampliaram o raciocínio sobre os perigos da homossexualidade e a associaram a um submundo de degenerados - 'pederastas', alcoólatras, prostitutas e outros desviantes e não conformistas - que representavam uma ameaça à segurança nacional” (BRASIL, 2014, p. 302, grifo meu).

Voltando ao diálogo com Quinalha, entendo que sua resposta na live traduz o cuidado excessivo de alguém que, por “não ser da área de história”, parece temer uma possível acusação de anacronia ${ }^{25}$. E certamente seria, por aqueles afeitos aos purismos, por não perceberem que esses são efeitos ideológicos que encobrem a luta de significações. Contudo, como disse Veyne (1998), a história não é uma ciência, não tem método, mas constitui uma tópica que se irrompe no científico e que, por isso, exige conceitualizações para melhor fazer compreender sua trama, e não sua temporalidade inalcançável.

Teorias, conceitos, tipos, esquematizações, tópicos são resumos das tramas, com necessário valor heurístico (para o autor) e didático (para o leitor). Por isso, os conceitos são sempre estranhos, limitados, parciais, restritivos, paradoxais. Somos impedidos, devido à opacidade da linguagem, de estabelecer limites determinados para os termos. Um conceito é sempre movimento. A crítica teria a função de castrá-lo, delimitá-lo, falar que certo emprego soa falso ou anacrônico... Ao fazer isso, é responsável pelo seu funcionamento paradoxal e heterogêneo: a tentativa frustrada de minar a emergência do acaso: “A organização dos eventos em categorias exige a historicização prévia dessas categorias, sob pena de uma classificação errônea ou de anacronismo. Da mesma maneira, empregar um conceito pensando que é suficientemente claro é arriscar um anacronismo implícito” (VEYNE, 1998, p. 112).

Herdeira tanto da hermenêutica bíblica como da teoria da pré-formação, a crítica historiográfica canônica goza, no sentido lacaniano, no dispositivo de legibilidade, reatualizando seu funcionamento sociopolítico excludente (LACAN, 1989). Ao tomar o acontecimento como objeto fechado em si, com sentidos dados e inscritos em sua pretensa textualidade documental, apaga-se e oblitera-se qualquer relação do analista com as condições de produção históricas. Assim como edifica o conceito (a palavra) em uma dimensão absolutista: o significado, ali

25 Ou, talvez, poderia indiciar, certas nuances, daquilo que Dodi Leal (2018, p. 124) chamou de CISplicação: "Especificamente no que se refere à linguagem transgêneras, temos uma correspondência corruptélica interessante: uma pessoa cis que tenta justificar-se com o intuito de passar ilesa ou sempre ser desculpada por não corresponder a uma solicitação de reconhecimento de gênero [...] quererá se explicar, ou CISplicar (fazer uma CISplicação visando manter seu privilégio). Vemos aqui uma aplicação efetiva do esgarçamento de opressões que tem na linguagem uma precisão extremamente elaborada de luta por reconhecimento”. Estaria Quinalha apenas se CISplicando? 
pretensamente inscrito, transpassaria imóvel pelo decurso temporal, sendo, assim, tomado como ‘representação’ de uma época.

Em posição radicalmente divergente, tal como Regine Robin (1977) convoca os historiadores, em História e linguística, não nos esqueçamos de considerar a materialidade da língua e da linguagem: as palavras se movimentam. Os sentidos derivam, possuem historicidade e se modificam nas diferentes conjunturas. Defender qualquer purismo linguístico, de fato, não seria pôr em jogo um anacronismo? E aqui me refiro à reflexão de Iago Moura e Maurício Beck (2019a, 2019b) a respeito da censura como forma anacrônica de calar o possível: é possível dizer $x$ sócio e historicamente, mas se interdita localmente essa possibilidade.

\section{Breves considerações}

Após esse percurso, por hora concluí que a formulação ‘ditadura hétero-militar’ não dá conta das políticas de gênero nem das complexas relações dessas com as políticas sexuais de intensificação da estrutura monolítica de interação social. Afinal, a ditadura radicalizou a prescrição cisgênero/heterossexual como único comportamento sexual e única identidade de gênero aceitáveis pelo regime, consistindo num cis-tema de significação estruturado em torno e por meio de princípios sociais, econômicos, culturais, políticos, religiosos, morais.

Caberia ainda mencionar que, em minha reescrituração, atribuo um valor conceitual distinto à grafia hifenizada dos termos, fazendo-a funcionar como tal no jogo com os demais conceitos que mobilizo. Num primeiro momento, tal nexo passou-me despercebido. Contudo, após refletir sobre o encadeamento daqueles elementos, ou seja, ao refletir sobre sua inseparabilidade como procedimento de veridiç̧ão (produção de verdade) e de sujeição (produção de sujeitos) atrelados à dinâmica dis-positiva, passei a considerar que, linguística e politicamente, o hífen tenta articular as complexidades e contradições dessa dimensão da ditadura brasileira. Um dos efeitos discursivos do hífen é produzir o sentido de inseparabilidade e cadeamento dos elementos interligados. Contudo, tal nexo preserva uma autonomia relativa dos elementos, apontando, assim, para as contradições. Nexo que se traduz no reconhecimento das políticas sexuais como inseparáveis das políticas de gênero e intrínsecas à forma-intraestatal no regime ditatorial: ‘cis-hétero-militarismo'.

Dessa forma, o hífen marca as interações constitutivamente contraditórias entre a cisgeneridade e a heterossexualidade no espectro da masculinidade militar, sinalizando tanto a aproximação quanto o distanciamento significante de (re)atualização da matriz cisgênera e heterossexual na construção da normalidade imaginária e delirante.

Por fim, menciono que acreditei, durante certo tempo, que com a expressão 'cis-hétero- 
militar’ sinalizava apenas para uma dimensão da ditadura brasileira, tal qual o conceito de Quinalha apontava. Hoje, não tenho certeza de ser possível reduzir toda essa confluência discursiva e não-discursiva a uma dimensão caracterizadora (adjetivo), mais ou menos organizada, do regime autoritário. Limitava-me a historicizar, tal qual Quinalha, sobre a emergência genética (diria, em meu caso, epigenética) no Brasil de uma homofobia de Estado, como política sexual, e de gênero, numa perspectiva individualizante que desprezaria o paradigma deimopolítico ${ }^{26}$ de significação das dissidências sexuais e de gênero como ameaças sociais: como se houvesse um ponto mais ou menos delimitado de surgimento, migração ou sequestração ${ }^{27}$ dessas políticas pelo aparato estatal.

Vejam que tal argumentação pressupunha uma clara delimitação entre as esferas estatal e extraestatal. No máximo, entendo agora que, na perspectiva de Louis Althusser (1985), talvez pudéssemos sustentar a existência de aparelhos ideológicos de Estado ramificados na estrutura social. Contudo, "Parece-me que o aparato estatal é uma forma concentrada, ou mesmo uma estrutura de apoio, de um sistema de poder que vai muito além e bem mais fundo” (FOUCAULT, 2015, p. 208). Disso decorre que, “na prática, nem o controle nem a destruição do aparato estatal podem bastar para causar a transformação ou o desaparecimento de certo tipo de poder, aquele dentro do qual ele funcionou” (FOUCAULT, 2015, p. 208). Postulado que será central na reflexão foucaultiana: embora seja um ponto de apoio basilar das relações de poder dominantes, o Estado não passa de uma peripeteia da governamentalidade, ou seja, uma circunstância ocasional da governamentalidade (FOUCAULT, 2008b).

Dessa forma, o mecanismo que possibilitou a emergência daquela dimensão cisgênera e heterossexual na ditadura brasileira é, em certo sentido, mais complexo, amplo e profundo do que a emergência histórica de políticas sexuais e de gênero (cis-heteronormadas) assumidas pelo Estado ou explicitamente visível em seus aparatos. Pouco importa saber se as instâncias sociais reproduzem ou repetem as estruturas estatais ou se seriam as estruturas do Estado que repetiriam tais instâncias. Há muito mais fluxos e indeterminações nessas relações mútuas de poder e de resistência. Todo ponto de exercício de poder é um lugar de indeterminação intraestatal.

26 Deimopolítica como os (re)arranjos simbólico-imaginários que visem à mobilização dos afetos coletivos em defesa da sociedade pela fabricação de inimigøs imaginários pela gestão política do binômio medo/esperança como difusor do pânico social (AFONSO-ROCHA, 2020a, 2021). Na mitologia grega, Deimos é o deus do Pânico

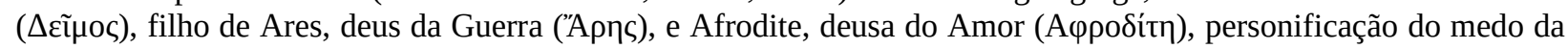
morte em batalha, irmão gêmeo e companheiro de luta de Fobos, o deus do Medo ( $\varphi$ óßos). A deimopolítica perverteria a lógica da vulnerabilidade: não somos nós, os dissidentes sexuais e de gênero, por exemplo, expostos diariamente ao risco da morte e da violência que estaríamos em perigo, mas somos nós que "representaríamos" ameaças às vidas normalizadas. Os assassinatos e demais violências, neste perverso funcionamento deimopolítico, nada mais seriam do que legítima defesa social em prol da "família", da sociedade e da nação.

27 Uso o termo tal qual Foucault (2015).

Periódicus, Salvador, n. 16, v.2, set.2021-dez.2021 - Revista de estudos indisciplinares em gêneros e sexualidades Publicação periódica vinculada ao Núcleo de Pesquisa NuCuS, da Universidade Federal da Bahia - UFBA ISSN: 2358-0844 - Endereço: http://www.portalseer.ufba.br/index.php/revistaperiodicus 
Como cansou de repetir Foucault, em tantas ocasiões que seria inadequado citar uma obra específica, o poder não está localizado nos aparatos estatais. Talvez respondendo Althusser, Foucault (2015, p. 12) escreveu em seu manuscrito do curso A sociedade punitiva: "Não era um aparato estatal, era um aparato preso no nó estatal. Um sistema intraestatal”. Em sentido semelhante, Claude Lefort (1979) mostrou que a oposição entre indivíduo e sociedade se revela como um falso problema, servindo a sustentação da relação de causalidade e exterioridade. Dessa forma, tal distinção apagaria sua atuação estrutural: a realidade objetiva social se sustenta numa mentalidade que a faz funcionar.

Assim, trata-se de um fenômeno mais profundo e constante do qual a dimensão 'cishétero-militar' da ditadura brasileira foi uma particularidade ou um efeito, erroneamente circunscrito ao aparato estatal. É preciso pensar o cis-hétero-militarismo para além da repressão estatal da ditadura brasileira. Compreendo-o como formação histórica ${ }^{28}$ sustentada numa norma ubuesco-pastoral $^{29}$, isto é, como tecnologia que determina comutações discursivas e nãodiscursivas, avultando dispositivos inúmeros: aliança, família, sexualidade, pastoral, perversão, masculinidade militar etc., de modo a produzir a coerência e naturalidade do cis-hétero-corpo; corpo esse que precisaria, nessa lógica, ser protegido da ameaça sexo-gendrada. Dessa forma, a dimensão mais ou menos delimitada da homofobia de estado se desvelaria igualmente presa em um nó estatal.

Por isso sustento que, numa perspectiva foucaultiana, a repressão aos sujeitos cisheterodissidentes (normação), bem como a produção de subjetividades cis-heteronormadas (normalização) durante a ditadura se deu numa complexa produção, atualização ${ }^{30}$, retroalimentação, ativação intraestatal das condições sócio-históricas de emergência dessa norma ubuesco-pastoral, explicitamente assumida naquele período como política de estado.

Com isso, aponto para o entrecruzamento dos mecanismos regulatórios da pastoral cristã $^{31}$ (a saber: a salvação do rebanho, a obediência à lei e a verdade do pastor) no cis-héteromilitarismo, cujos efeitos produtivos são a necessidade de 'salvar' o cidadão ameaçado e a criação da 'verdade' do regime (na imagem das Forças Armadas como 'pastor') pela 'obediência' aos valores nacionais, judaico-cristãos. A isso, soma-se o grotesco (ubuesco), ou seja, o perverso como racionalidade política de governamentalidade.

28 Sobre o conceito de formação histórica, consultar Deleuze (2017); a respeito do cis-hétero-militarismo como formação histórica de significação dominante, logo imaginária, da dissidência sexual e de gênero no Brasil após 1930, ver Afonso-Rocha (2020b, 2021).

29 Penso no curso que Michel Foucault (2018) ministrou em 1974-1975, “Os anormais”. Nas duas primeiras aulas desse curso, Foucault refletiu sobre aquilo que chamou de poder ubuesco, que traduzia a tecnologia política pela intensificação do grotesco e do risível. O neologismo foucaultiano remete à peça teatral Ubu-roi, de Alfred Jarry.

30 Uso ‘atualização’ como materialização de uma virtualidade, no sentido foucaultiano (2008a).

31 Sobre o poder pastoral, consultar Foucault (2017).

Periódicus, Salvador, n. 16, v.2, set.2021-dez.2021 - Revista de estudos indisciplinares em gêneros e sexualidades Publicação periódica vinculada ao Núcleo de Pesquisa NuCuS, da Universidade Federal da Bahia - UFBA ISSN: 2358-0844 - Endereço: http://www.portalseer.ufba.br/index.php/revistaperiodicus 
Tal funcionamento não ficou restrito aos anos de exceção: em seus atravessamentos, atualizações e entrecruzamentos em outras formações históricas, ele persiste e insiste em nunca acabar. É aquilo que assombra e, infelizmente, fascina.

Não poderia fechar, ainda que imaginariamente, este texto sem expor os limites da minha crítica: tal qual Quinalha, sou interpelado por identificações cisgêneras. Fato que certamente dificulta minha investigação. Ao longo desse texto, busquei ‘falar com’ as e os intelectuais trans, de modo a minorar os efeitos castradores do 'cis-jeito' ${ }^{32}$ pelos quais sou constituído e interpelado. Claro que toda apropriação do pensamento outro, nessa ilusória homogeneidade, corre o risco de atualizar-se como epistemicídio ${ }^{33}$. Por isso gostaria de registrar que as discussões aqui realizadas não dispensam, sob nenhuma justificativa, a leitura de pesquisadoras e pesquisadores trans ${ }^{34}$. Talvez, este texto não passe de mais uma cis-plicação.

Por fim, cabe mencionar que Renan Quinalha escreveu o posfácio do meu livro O perigo cor-de-rosa: ensaios sobre a deimopolítica, a ser publicado em 2021 pela editora Devires, no qual rebate e discute as críticas que faço ao seu trabalho. O texto de Quinalha, Quanta diferença faz um "cis"?, apresenta uma contra-crítica bastante interessante e que muito contribui com o enriquecimento do pensamento crítico sobre as relações entre ditadura e dissidências sexogendradas.

\section{Referências}

ACOSTA, A. Bom mesmo é carne de homem. Lampião da Esquina. Rio de Janeiro, n. 17, p. 16, out. 1979. Seção Bixórdia.

AFONSO-ROCHA, R. Bichas inauguram a utopia. 2018. Trabalho de conclusão de curso (Bacharelado em Direito) - Universidade Estadual de Santa Cruz, Ilhéus, 2018.

AFONSO-ROCHA, R. Bichas também sangram: deimopolítica e direito de resistência na literatura "homossexual” do jornal Lampião da Esquina. 2020. Dissertação (Mestrado em Letras: Linguagens e Representações) Universidade Estadual de Santa Cruz, Ilhéus, 2020a.

32 Termo utilizado por Sara Wagner York, em post do Facebook, como corruptela de linguagem para demarcar que a categoria analítica e filosófica do 'sujeito', em sua pretensa homogeneidade e universalidade, desvela-se excludente e castradora, sinalizando, com isso, a dimensão cisgênera que atravessa a interpelação.

33 Sobre o conceito de epistemicídio, ver Suely Carneiro (2005).

34 Para uma excelente discussão sobre o deslocamento da posição de 'pesquisadas' para 'pesquisadoras' ensejado pelas travestis intelectuais no Brasil, consultar Sofia Favero (2020, p. 18): "Pleitear a ética do pajubá consiste em macular a neutralidade cisgênera. Ela representa uma postura que não dá ekês, ou seja, que não se ausenta, pois é uma espectadora assídua desde o processo de elaboração de uma pergunta de pesquisa até a análise dos dados, escrita, defesa, enfim. Pajubar uma ética é um movimento que indica o corpo ao exame, mas que também se vale das alianças para profusão de conhecimentos". 
AFONSO-ROCHA, R. O perigo cor-de-rosa: ensaios sobre deimopolítica. Salvador: Devires, 2021. (No prelo).

AFONSO-ROCHA, R. Risco da bixa: o inimigo homossexual como invenção política. Resista! - Observatório de Resistências Plurais, [s. l.], 2020b. Disponível em: https://bit.ly/2URcjF7. Acesso em: 17 set. 2020.

AFONSO-ROCHA, R; MITIDIERI, A. Bichas inauguram a utopia: resistência homoerótica na literatura lampiônica. Raído, v. 13, n. 32, p. 47-72, 2019.

ALTHUSSER, L. Aparelhos ideológicos de Estado. Rio de Janeiro: Graal, 1985.

AZEVEDO, B. Travesti protesta. Lampião da Esquina, Rio de Janeiro, n. 18, p. 19, nov. 1979. Seção Carta na Mesa.

BAGAGLI, B. Cisgeneridade e silêncio. Transfeminismo, [s. l.], 18 abr. 2014. Disponível em: https://bit.ly/3kplF5p. Acesso em: 25 set. 2020.

BAGAGLI, B. Máquinas discursivas, ciborgues e transfeminismo. Revista Gênero, Niterói, v. 14, n. 1, p. 11-27, 2016.

BAKHTIN, M; VOLOCHÍNOV, V. N. Marxismo e filosofia da linguagem. Tradução de Michel Teixeira Wisnik e Carlos Henrique D. Chagas Cruz. 2. ed. São Paulo: Hucitec, 1981.

BOITO JÚNIOR, A. Indicações para o estudo do marxismo de Althusser. In: PINHEIRO, J. (org.). Ler Althusser. São Paulo: Cultura Acadêmica, 2016. p. 151-182.

BRASIL. Ditadura e homossexualidades. Brasília, DF: Comissão Nacional da Verdade, 2014.

BRASIL. Serviço de Censura de Diversões Públicas (SCDP). Parecer $n^{\circ}$ 523/75 (letras musicais). Brasília, DF: Arquivo Nacional; Fundo Serviço de Censura de Diversões Públicas, 1975a.

BRASIL. Serviço de Censura de Diversões Públicas (SCDP). Parecer $n^{\circ}$ 524/75 (letras musicais). Brasília, DF: Arquivo Nacional; Fundo Serviço de Censura de Diversões Públicas, 1975b.

BRASIL. Serviço Nacional de Informação (SNI). Propaganda adversa, literatura (período de jan a abr 85). Brasília, DF: Fundo Serviço Nacional de Informações, 1985.

BUTLER, J. Corpos que importam: os limites discursivos do "sexo”. São Paulo: N-1 Edições, 2019.

CABRAL, J. R. Arquivos da repressão: representações sociais da diversidade sexual e de gênero na ditadura militar. In: SEMINÁRIO DE 
SABERES ARQUIVÍSTICOS, 8., 2017, João Pessoa. Anais [...]. João Pessoa: UFPB, 2017.

CANABARRO, R. P.; MEYRER, M. R. Travesti: textos-vestígios na construção de uma identidade - Jornal Lampião da Esquina (1978-1981). Revista Tempo e Argumento, Florianópolis, v. 12, n. 29, p. 1-29, 2020.

CARNEIRO, A. S. A construção do outro como não-ser como fundamento do ser. 2005. Tese (Doutorado em Filosofia) - Universidade de São Paulo, 2005.

CHRYSÓSTOMO, A. Mônica Valéria, uma vida em segredo. Lampião da Esquina, Rio de Janeiro, n. 7, p. 10, 1978.

COWAN, B. Homossexualidade, ideologia e subversão no regime militar. In: GREEN, J.; QUINALHA, R. (org.). Ditadura $e$ homossexualidades: repressão, resistência e a busca da verdade. São Carlos: EdUFSCAR, 2015. p. 27-52.

CUNHA, N.; YORK, S. W. Um vácuo ‘cis’ na história e a emergência do corpo trans. Rosalux, São Paulo, 17 nov. 2020. Disponível em: https://bit.ly/3idtKaJ. Acesso em: 21 nov. 2020.

CURIEL, O. La nación heterosexual. Análisis del discurso jurídico y el régimen heterosexual desde la antropología de la dominación. Bogotá: Brecha Lésbica, 2013.

DANIEL, H. Passagem para o próximo sonho: um possível romance autocrítico. Rio de Janeiro: Codecri, 1982.

DELEUZE, G. Michel Foucault: as formações históricas. São Paulo: N-1 Edições, 2017.

FACHINI, R. Sopa de letrinhas: movimento homossexual e produção de identidades coletivas nos anos 90. Rio de Janeiro: Garamond, 2005.

FAVERO, S. Por uma ética pajubariana: a potência epistemológica das travestis intelectuais. Equatorial: Revista do Programa de Pós-Graduação em Antropologia Social, Natal, v. 7, n. 12, p. 1-22, 2020.

FERREIRA, L. S. Mem(orais): poéticas de uma byxa-travesty preta de cortes. São Paulo: Urutau, 2019.

FIORIN, J. L. O regime de 1964: discurso e ideologia. São Paulo: Atual, 1988.

FOUCAULT, M. A arqueologia do saber. Tradução de Luiz Felipe Baeta Neves. Rio de Janeiro: Forense Universitária, 2008a.

FOUCAULT, M. A sociedade punitiva: curso no Collège de France (1972-1973). Tradução de Maria Ermantina Galvão. São Paulo: Martins Fontes, 2015. 
FOUCAULT, M. História da Sexualidade 1: a vontade de saber. Tradução de Maria Thereza da Costa Albuquerque e Guilhon Albuquerque. Rio de Janeiro: Paz e Terra, 2017.

FOUCAULT, M. Os anormais: curso no Collège de France (1974-1975). Tradução de Eduardo Brandão. São Paulo: Martins Fontes, 2018.

FOUCAULT, M. Segurança, território, população: curso no Collège de France (1976-1977). Tradução de Maria Ermantina Galvão. São Paulo: Martins Fontes, 2008b.

GREEN, J. Além do carnaval: a homossexualidade masculina no Brasil do século XX. São Paulo: UNESP, 2000.

HOCQUENGHEM, G. Entrevista ao Lampião da Esquina. Hocquenghem: Revolucionário é o travesti. Lampião da Esquina, Rio de Janeiro, n. 37, p. 6-7, 1980.

IRVIN-ERICKSON, D. Genocide, the 'family of mind' and the romantic signature of Raphael Lemkin. Journal of Genocide Research, [s. l.], v. 15, n. 3, p. 273-296, 2013.

JESUS, J. G. Travessia: caminhos da população trans na história. In: GREEN, J. N. et al. História do movimento LGBT no Brasil. São Paulo: Alameda, 2018. p. 379-392.

KUCINSKI, B. Jornalistas e revolucionários da imprensa brasileira. São Paulo: Escrita, 1991.

LACAN, J. O seminário, livro 20: mais, ainda. Rio de Janeiro: Zahar, 1989.

LANZ, L. O corpo da roupa: a pessoa transgênera entre a conformidade e a transgressão das normas de gênero. Uma introdução aos estudos transgêneros. Curitiba: Transgente, 2015.

LEAL, D. T. B. Performatividade transgênera: equações poéticas de reconhecimento recíproco na recepção teatral. 2018. Tese (Doutorado em Psicologia) - Universidade de São Paulo, São Paulo, 2018.

LEFORT, C. As formas da história: ensaios de antropologia política. Brasília, DF: Brasiliense, 1979.

LOPES, F. H. Travestilidades e ditadura civil-militar brasileira. Apontamentos de uma pesquisa. Esboços: Histórias em Contextos Globais, Florianópolis, v. 23, n. 35, p. 145-167, 2016.

MARIANI, B. O comunismo imaginário: práticas discursivas da imprensa sobre o PCB (1922-1989). 1996. Tese (Doutorado em linguística) - Universidade de Campinas, Campinas, 1996. 
MASCARENHAS, J. A. Sobre tigres de papel. Lampião da Esquina, Rio de Janeiro, n. 4, p. 9, set. 1978.

MOIRA, A. R. O cis pelo trans. Estudos Feministas, Florianópolis, v. 25, n. 1, p. 365-373, 2017.

MORANDO, L. Por baixo dos panos: repressão a gays e travestis em Belo Horizonte (1963-1969). In: GREEN, J.; QUINALHA, R. (org.). Ditadura e homossexualidades: repressão, resistência e a busca da verdade. São Carlos: EdUFSCAR, 2015. p. 53-82.

MOURA, I.; BECK, M. Auscultar vestígios: a especificidade significante do silêncio na divisão do trabalho semântico. In: SEMINÁRIO DE ESTUDOS EM ANÁLISE DO DISCURSO (SEAD), 9., 2019, Recife. Anais [...]. Recife: UFPE, 2019a. p. 1-7. Disponível em: https://bit.ly/3rm7qQr. Acesso em: 8 maio 2020.

MOURA, I.; BECK, M. Vestígios do silêncio. RUA, Campinas, v. 25, n. 1, p. 137-165, 2019b.

NERY, J. W. Transmasculinos: invisibilidade e luta. In: GREEN, J. N. et al. História do movimento LGBT no Brasil. São Paulo: Alameda, 2018. p. 393-404.

OCANHA, R. F. “Amor, feijão, abaixo camburão” - Imprensa violência e trottoir em São Paulo (1979-1983). 2014. Dissertação (Mestrado em História). Pontifícia Universidade Católica de São Paulo, São Paulo, 2014.

OCANHA, R. F. As rondas policiais de combate à homossexualidade na cidade de São Paulo (1976-1982). In: GREEN, J.; QUINALHA, R. (org.). Ditadura e homossexualidades: repressão, resistência e a busca da verdade. São Carlos: EdUFSCAR, 2015. p. 149-176.

ORLANDI, E. P. Discurso e leitura. 7. ed. São Paulo: Cortez, 2006.

PEIXE, A.; MORELLI, F. "Homens do Futuro": o movimento de homens trans no Brasil sob o olhar de Xande Peixe. In: GREEN, J. N. et al. História do movimento LGBT no Brasil. São Paulo: Alameda, 2018. p. $405-420$.

PERLONGHER, N. O desaparecimento da homossexualidade. In: LANCETTI, A. et al. Saúde Loucura. São Paulo: Hucitec, 1993, P. 3946.

PRECIADO, P. B. Um apartamento em Urano: crônicas da travessia. Companhia das Letras, 2020.

QUINALHA, R. A questão LGBT no trabalho de memória e justiça após a ditadura brasileira. In: GREEN, J.; QUINALHA, R. (org.). Ditadura e homossexualidades: repressão, resistência e a busca da verdade. São Carlos: EdUFSCAR, 2015. p. 245-272. 
QUINALHA, R. Contra a moral e os bons costumes: a política sexual da ditadura brasileira (1964-1988). 2017. Tese (Doutorado em Relações Internacionais) - Instituto de Relações Internacionais, Universidade de São Paulo, São Paulo, 2017.

QUINALHA, R. Posfácio: quanta diferença faz um “cis”? In: AFONSOROCHA, R. $O$ perigo cor-de-rosa: ensaios sobre deimopolítica. Salvador: Devires, 2021, p. 242-248. (No prelo).

QUINALHA, R. Uma ditadura hétero-militar: notas sobre a política sexual do regime autoritário brasileiro. In: GREEN, J. N. et al. História do movimento LGBT no Brasil. São Paulo: Alameda, 2018. p. 15-38.

RICH, A. Heterossexualidade compulsória e existência lésbica. Bagoas Estudos Gays: Gênero e Sexualidades, Natal, v. 4, n. 5, p. 17-44, 2010.

RIO DE JANEIRO. Comissão Estadual da Verdade. Ditadura $e$ homossexualidades. Rio de Janeiro: CEVRJ, 2015.

ROBIN, R. História e lingüística. São Paulo: Cultrix, 1977.

RODRIGUES, R. C. De Daniele a Chrysóstomo: quando travestis, bonecas e homossexuais entram em cena. 2012. Tese (Doutorado em História Social) - Universidade Federal Fluminense, Rio de Janeiro, 2012.

RODRIGUES, R. C. De Denner a Chrysóstomo, a repressão invisibilizada: as homossexualidades na ditadura. In: GREEN, J.; QUINALHA, R. (org.). Ditadura e homossexualidades: repressão, resistência e a busca da verdade. São Carlos: EdUFSCAR, 2015. p. 201244.

SÃO PAULO. Comissão Estadual da Verdade Rubens Paiva. Ditadura e homossexualidades. São Paulo: CEVSP, 2015.

SHOCK, S. Poemario trans pirado. Buenos Aires: Nuevos Tiempos, 2011.

SILVA, A. Síndico quer Verushka usando gravata e paletó. Lampião da Esquina, Rio de Janeiro, n. 10, p. 3, mar. 1979.

SILVA, A. Turno da noite: memórias de um ex-repórter de polícia. Rio de Janeiro: Objetiva, 2016.

SILVA, E.; BRITO, A. Travestis e transexuais no jornal 'Lampião da Esquina' durante a ditadura militar (1978-1981). Dimensões, Vitória, n. 38, p. 214-239, 2017.

SIMAKAWA, V. V. Por inflexões decoloniais de corpos e identidades de gênero inconformes: uma análise autoetnográfica da cisgeneridade como normatividade. 2015. Dissertação (Mestrado em Cultura e Sociedade) - Universidade Federal da Bahia, Salvador, 2015. 
TREVISAN, J. S. Devassos no paraíso: a homossexualidade no Brasil, da colônia à atualidade. Rio de Janeiro: Objetiva, 2018.

VEYNE, P. Foucault revoluciona a história e como se escreve a história. Brasília, DF: Cadernos da UNB, 1998.

VEYNE, P. Foucault: seu pensamento, sua pessoa. Rio de Janeiro: Civilização Brasileira, 2011.

VIDARTE, P. Ética bixa: proclamações libertárias para uma militância LGBTQ. São Paulo: N-1 edições, 2019.

VIEIRA, H.; FRACCAROLI, Y. Violência e dissidências: um breve olhar às experiências de repressão e resistência das travestis durante a ditadura militar e os primeiros anos da democracia In: GREEN, J. N. et al. História do movimento LGBT no Brasil. São Paulo: Alameda, 2018. p. 357-378.

WARNER, M. Introduction: fear of a queer planet. Social Text, [s. l.], n. 29, p. 3-17, 1991.

WITTIG, M. El pensamiento heterossexual y outros ensayos. Madrid: Egales, 1982.

YORK, S. W. No mar dos abandonos. Rebeh: Revista Brasileira de Estudos da Homocultura, Redenção, v. 1, n. 1, p. 79-90, 2018. 